\title{
Glucose-induced changes in renal haemodynamics in proteinuric Type 1 (insulin-dependent) diabetic patients: inhibition by acetylsalicilic acid infusion
}

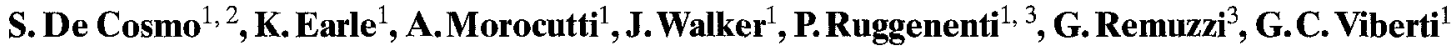 \\ ${ }^{1}$ Unit for Metabolic Medicine, United Medical and Dental School, Guy's Hospital, London, UK \\ ${ }^{2}$ Department of Medicine, I.R.C.C.S. "Casa Sollievo della Sofferenza" San Giovanni Rotondo, Italy \\ ${ }^{3}$ Istituto Mario Negri, Bergamo, Italy
}

Summary. The effect of hyperglycaemia on renal function in diabetic nephropathy remains poorly understood. We investigated the renal haemodynamic response to an acute plasma glucose rise from sustained euglycaemia to sustained hyperglycaemia in eight persistently proteinuric Type 1 (insulindependent) diabetic patients. Studies were performed in a double-blind cross-over manner after i. v. injection of $450 \mathrm{mg}$ lysine acetylsalicilate (equivalent to $250 \mathrm{mg}$ acetylsalicilic acid) or equal volume of $0.9 \% \mathrm{NaCl}$ (isotonic saline). In the isotonic saline experiments hyperglycaemia produced a significant rise, by approximately $35 \%$, in glomerular filtration rate in all patients from $41.5 \pm 5.2$ to $55 \pm 6 \mathrm{ml} \cdot \mathrm{min}^{-1} \cdot 1.73 \mathrm{~m}^{-2}$ $(p<0.005)$ and an increase in sodium paraminohippurate clearance from $178 \pm 22.7$ to $220 \pm 20.0 \mathrm{ml} \cdot \mathrm{min}^{-1} \cdot 1.73 \mathrm{~m}^{-2}$ $(p<0.05)$. These changes took place within the first $30 \mathrm{~min}$ of glucose infusion and were maintained for a 90 min hyperglycaemic period. Filtration fraction did not change significantly. Infusion of lysine acetylsalicilate lowered baseline glome- rular filtration rate (isotonic saline vs lysine acetylsalicilate $41.5 \pm 5.2$ vs $\left.30.0 \pm 5.7 \mathrm{ml} \cdot \mathrm{min}^{-1} \cdot 1.73 \mathrm{~m}^{-2} ; p<0.05\right)$ and significantly blunted the rise in glomerular filtration rate during hyperglycaemia (glomerular filtration rate increment: saline vs lysine acetylsalicilate: $13.6 \pm 2.8$ vs $5.3 \pm 1.8 \mathrm{ml} \cdot \mathrm{min}^{-1}$ $.1 .73 \mathrm{~m}^{-2} ; p<0.005$ ). The effects on renal plasma flow were similarly blunted. In five additional patients, time- and volume-controlled isotonic saline experiments during sustained euglycaemia showed no significant changes in glomerular filtration rate and sodium paraminohippurate clearance. In Type 1 diabetic patients with advanced renal failure, acute hyperglycaemia induces a significant elevation in glomerular filtration rate and renal plasma flow which is likely to be mediated by renal prostaglandin production.

Key words: Diabetic nephropathy, renal haemodynamics, Type 1 (insulin-dependent) diabetes mellitus, lysine-acetylsalicilate, hyperglycaemia.
An elevation of plasma glucose has been implicated in the modulation of glomerular filtration rate (GFR) in early diabetes mellitus and may contribute to the genesis of diabetic glomerular hyperfiltration $[1,2]$, a phenomenon believed to be a precursor of clinical nephropathy [3, 4]. Both acute and chronic lowering of blood glucose to nearnormal levels significantly reduces GFR in normoalbuminuric Type 1 (insulin-dependent) diabetic patients with normal or elevated GFR [5-8].

Recently we have shown that plasma glucose is also important in regulating GFR in Type 1 diabetic patients with advanced nephropathy. High levels of plasma glucose were found to be associated with significant elevations in GFR which were brought about by an increase both in membrane permeability to small macromolecules and in the glomerular ultrafiltration coefficient $\left(\mathrm{K}_{\mathrm{f}}\right)$ [9].

The present study was designed to investigate the time course of glucose-induced renal haemodynamic changes and the role of prostaglandins as potential mediators of these changes in Type 1 diabetic patients with overt nephropathy.

\section{Subjects and methods}

\section{Patients}

Type 1 diabetic patients with persistent proteinuria (total protein excretion $>0.5 \mathrm{~g} / 24 \mathrm{~h}$ ) and ${ }^{51} \mathrm{Cr}$ EDTA GFR below $70 \mathrm{ml} \cdot \mathrm{min}^{-1}$ $.1 .73 \mathrm{~m}^{-2}$, recruited from our cohort of diabetic patients with renal failure in the Unit for Metabolic Medicine at Guy's Hospital, were asked to take part in the study.

Eight (five male, three female) patients aged between 38 and 58 years (mean 48 years) gave their informed consent to the study which was approved by the ethics committee of Guy's Hospital. Duration of diabetes was 26 years (range 19-30 years), urinary protein excretion was $1.3 \mathrm{~g} / 24 \mathrm{~h}$ (range $0.7-3.0$ ) and GFR (clearance of ${ }^{51} \mathrm{Cr}$-labelled edetic acid) was $38.3 \mathrm{ml} \cdot \mathrm{min}^{-1} \cdot 1.73 \mathrm{~m}^{-2}$ (range $25.5-$ 68.2). Other renal disease and heart failure were excluded by clinical and biochemical tests. Renal biopsies taken from three patients, 
showed diabetic histological changes only. Four patients had preproliferative and four had proliferative retinopathy. All the patients had been treated with insulin since diagnosis and at the time of the study were receiving antihypertensive treatment with beta-blockers and diuretics (four patients) beta-blockers, diuretics and angiotensinconverting enzyme inhibitors (three patients), beta-blockers, calcium-channel blockers and diuretics (one patient). All antihypertensive drugs were stopped for at least $36 \mathrm{~h}$ before the acute studies. Glycated haemoglobin level, measured by electroendosmosis (Corning Chemical, Palo Alto, Calif., USA), ranged from 7.2 to $9.6 \%$ (mean $8.4 \%$ ) and sodium intake varied from 90 to $110 \mathrm{mmol} /$ day (mean $105 \mathrm{mmol} /$ day).

\section{Study design and experimental procedures}

The renal haemodynamic and proteinuric response to an acute glycaemic change from sustained euglycaemia to sustained hyperglycaemia was measured after an i.v. injection of $450 \mathrm{mg}$ lysineacetylsalicilate (LAS) (equivalent to $250 \mathrm{mg}$ acetylsalicilic acid) in $2.5 \mathrm{ml}$ of $0.9 \% \mathrm{NaCl}$ (isotonic saline) or of an equivalent volume of isotonic saline in a double blind, randomized, cross-over study. An interval of at least 2 weeks elapsed between the two studies. Four patients received lysine-acetylsalicilate first and four patients isotonic saline.

Patients were admitted to a metabolic ward at 18.00 hours the day before the study. A teflon cannula (Venflon; Viggo, Helsingborg, Sweden) was inserted under local anaesthesia into an antecubital vein in each arm, one for blood sampling and the other for infusion. The usual evening insulin injection was omitted and a low-dose infusion of insulin (Actrapid HM; Novo, Copenhagen, Denmark) commenced before the evening meal to maintain plasma glucose at around $4.5 \mathrm{mmol} / \mathrm{l}$ (between 3.5 and $5.5 \mathrm{mmol} / \mathrm{l}$ ) overnight.

The overnight insulin infusion rate of $0.92 \pm 0.4 \mathrm{IU} / \mathrm{h}$ was continued throughout the study which started the next morning at around 07.00 hours after the patients had remained fasting and without tea, coffee and smoking but not tap water since 22.00 hours the previous night.

After a steady-state diuresis of between 5.3 and $10.8 \mathrm{ml} / \mathrm{min}$ (mean $7.2 \mathrm{ml} / \mathrm{min}$ ) was obtained by an infusion of isotonic saline $(0.9 \% \mathrm{NaCl})$ at $400 \mathrm{ml} / \mathrm{h}$, measurements of GFR and effective renal plasma flow (ERPF) were started using the constant infusion technique for polyfructosan and sodium paraminohippurate (PAH) as previously described [10]. Briefly, a bolus dose of polyfructosan (Inutest; Boheringer-Mannheim, Zurich, Switzerland) $3.5 \mathrm{mg}$ in $35 \mathrm{ml}$ of water and paraminohippurate (PAH; Merck Sharpe and Dohme, Hoddesdon, Herts., UK) $600 \mathrm{mg}$ in $3 \mathrm{ml}$ of water were followed by a constant infusion of Inutest and $\mathrm{PAH}$ in isotonic saline to maintain plasma concentration of 35 and $2 \mathrm{mg} / \mathrm{dl}$, respectively. After 60-min equilibration, isotonic saline or LAS were injected i.v. and timed 30-min urine collections were started. Three measurements were taken during euglycaemia and three during sustained hyperglycaemia. Blood glucose was raised to levels of moderate hyperglycaemia, previously shown to be associated with increased GFR in early diabetes [11], by a graded infusion of dextrose $(2778 \mathrm{mmol} / \mathrm{l})$ as described by De Fronzo et al. [12] and maintained by continuous adjustment of dextrose infusion rate (range 12 to 48 , mean $28 \mathrm{ml} / \mathrm{h}$ ) based on frequent measurements of glycaemia. The total glucose infused to raise glycaemia and to maintain hyperglycaemia was similar in the two studies and varied between 609 and $2438 \mathrm{mmol}$ (mean $1422 \mathrm{mmol}$ ). The urine collected during the 20 -min interval required to raise blood glucose to hyperglycaemic levels was discarded. The means of all three periods for each patient during euglycaemia or hyperglycaemia as well as individual collection time intervals were used for calculations. Urine volume was immediately measured to the nearest $2 \mathrm{ml}$ and aliquots taken into tubes containing $10 \mu \mathrm{l}$ of $4 \mathrm{~mol} / 1 \mathrm{NaOH}$ to avoid loss of free $\mathrm{PAH}$ in glycosuric urine [13], for measurements of PAH and polyfructosan. A further $3.5 \mathrm{ml}$ aliquot was taken into a tube containing $20 \mu \mathrm{l}$ gelatine $(10 \% \mathrm{weight} / \mathrm{vol}-$ ume) for measurement of urinary albumin and IgG concentration, which were therefore determined simultaneously with the renal haemodynamic parameters. At the midpoint of each urine collection period, pulse rate and supine blood pressure (phase I/V) to the nearest $2 \mathrm{~mm} \mathrm{Hg}$ using a standard mercury sphygmomanometer, were taken by a single observer (SDC), and blood samples were drawn for measurement of $\mathrm{PAH}$, polyfructosan, glucose, total protein, haematocrit, albumin and IgG.

In five additional male Type 1 diabetic patients with proteinuria aged 44 to 60 years (mean 50 years), with duration of diabetes ranging 27-34 years (mean 31 years), total urinary protein excretion between 0.5 and $2.4 \mathrm{~g} / 24 \mathrm{~h}$ (mean 1.2) and mean GFR $43.2 \mathrm{ml} \cdot \mathrm{min}^{-1}$ $.1 .73 \mathrm{~m}^{-2}$ (range 22-69), time- and volume-controlled experiments were carried out. These patients, who from the clinical and biochemical standpoint for both diabetes and renal disease were strictly comparable to the other group underwent exactly the same experimental procedures as used in the isotonic saline experiments except that euglycaemia was maintained for $3 \mathrm{~h}$ and $20 \mathrm{~min}$. The urine collected in the 20-min interval between the two euglycaemic periods was discarded as in the hyperglycaemic experiments. Insulin infusion rate was $0.88 \pm 0.5 \mathrm{IU} / \mathrm{h}$ and diuresis ranged between 5.6 and $11.4 \mathrm{ml} / \mathrm{min}$ (mean $7.8 \mathrm{ml} / \mathrm{min}$ ). In the control experiments urine was not collected for albumin and IgG determinations. All subjects remained supine throughout the study standing only to void urine.

\section{Measurements and calculations}

Plasma and urine polyfructosan were measured after perchloric acid hydrolysis using a centrifugal analyser (Cobas Mira; Roche Diagnostica, Welwin Garden City, Herts., UK) as previously described [14]. Plasma and urinary PAH were measured using the method of Bratton and Marshall [15] adapted for use on a Cobas Bio centrifugal analyser (Roche Diagnostica). Inter- and intraassay coefficient of variation were 3.6 and $3.1 \%$, respectively for Inutest and 4.0 and $3.1 \%$ for PAH. Glucose was measured by a glucose oxidase method (Yellow Spring Analyzer; Yellow Springs Instruments Inc, Yellow Springs Ohio, USA), haematocrit by routine coulter counter, and total plasma protein by reflectometry. Plasma albumin and $\operatorname{IgG}$ were measured on the Cobas Bio Analyser (Roche Diagnostica), urinary albumin by an immunoturbidimetric method [16] and urinary IgG by an ELISA technique using a modification of the method of Voller et al. [17]. GFR and ERPF were calculated as the clearances of polyfructosan and $\mathrm{PAH}$, respectively, using the standard formula UV/P and corrected to $1.73 \mathrm{~m}^{2}$ body surface area. Filtration fraction (FF) was calculated as inulin clearance divided by PAH clearance.

Albumin and IgG excretion rates were calculated as urinary concentration $\times$ urine flow rate and their fractional clearance was obtained by dividing their clearance by the GFR.

Renal vascular resistance was calculated as $\mathrm{MBP} \times(1-\mathrm{Hct}) /$ ERPF, where MBP is mean blood pressure (diastolic blood pressure + one-third the pulse pressure) and Hct is haematocrit.

\section{Statistical analysis}

Analysis of variance was used to test for differences in renal haemodynamic parameters between studies and between the two glycaemic conditions. The Student's $t$-test for paired data was used to compare individual experimental conditions in the hyperglycaemic studies. Values of urinary albumin and IgG were log-transformed before statistical analysis. Statistical significance was defined as $p<0.05$. All results are expressed as mean \pm SEM unless otherwise stated.

\section{Results}

Similar levels of baseline euglycaemia at approximately $4.5 \pm 0.3 \mathrm{mmol} / 1$ and of glucose-induced hyperglycaemia at approximately $15.5 \pm 0.5 \mathrm{mmol} / \mathrm{l}$ were obtained in the 
isotonic saline and LAS studies. In the control experiments euglycaemia was maintained throughout at a level of $4.9 \pm 0.4 \mathrm{mmol} / \mathrm{l}$.

A stable diuresis was maintained in all patients, the average variation $(95 \% \mathrm{CI})$ of urine flow in individual studies was $24.8 \%(10-31)$ and there were no differences between studies. The mean $(95 \% \mathrm{CI})$ coefficient of variation of GFR during euglycaemia and hyperglycaemia was $19 \%(14-30)$ and $12 \%(7-21)$ in the isotonic saline study and $17 \%(10-24)$ and $16 \%(7-25)$ in the LAS study, respectively. These differences were not significant. Similarly the coefficients of variation of PAH clearance were comparable between studies and averaged 14\% (4-24) during euglycaemia and 19\% (10-28) during hyperglycaemia in the isotonic saline study and $21 \%(15-27)$ and $19 \%$ (11-27) in the LAS study, respectively. In the euglycaemia isotonic saline control study the coefficient of variation for GFR averaged 13\% (11-15) and for PAH 16\% (9-25).

In the isotonic saline study GFR rose during hyperglycaemia by approximately $35 \%$ from $41.5 \pm 5.2$ to $55.0 \pm$ $6.0 \mathrm{ml} \cdot \mathrm{min}^{-1} \cdot 1.73 \mathrm{~m}^{-2}(p<0.005)$ (Table 1$)$. The rise occurred within the first 30 min of hyperglycaemia and was sustained for the duration of the study (30 min: $62.5 \pm 4$ $(p<0.005), 60 \mathrm{~min}: 52.2 \pm 6 \quad(p<0.05), 90 \mathrm{~min}: 52 \pm 5$ $\left.(p<0.05) \mathrm{ml} \cdot \mathrm{min}^{-1} \cdot 1.73 \mathrm{~m}^{-2}\right)$. After LAS administration baseline GFR during euglycaemia was lower than in the isotonic saline control study at $30.0 \pm 5.7 \mathrm{ml} \cdot \mathrm{min}^{-1}$ $.1 .73 \mathrm{~m}^{-2}(p<0.05)$ and rose by approximately $23 \%$ to $35.4 \pm 6.0 \mathrm{ml} \cdot \mathrm{min}^{-1} \cdot 1.73 \mathrm{~m}^{-2}$ during hyperglycaemia $(p<0.05)$ (Table 1). The GFR increment during hyperglycaemia was significantly blunted by LAS infusion (isotonic saline vs LAS $13.6 \pm 2.8$ vs $5.3 \pm 1.8 \mathrm{ml} \cdot \mathrm{min}^{-1}$ $.1 .73 \mathrm{~m}^{-2}(p<0.005)$. The percent change of GFR during hyperglycaemia was of significantly smaller magnitude in the LAS study. The GFR change at $30 \mathrm{~min}$ after hyperglycaemia was larger in the isotonic saline compared to the LAS study (isotonic saline vs LAS, mean \pm SD $54 \pm 15 \%$ vs $17 \pm 10 \% ; p<0.05)$ and the overall percent change over the 90-min period of hyperglycaemia expressed as area under the curve, greater $(2910 \pm 567$ vs $2149 \pm 558$ $p<0.05$ ) (Fig. 1).

In the euglycaemia isotonic saline control study GFR showed insignificant variations between the first 90-min (mean \pm SEM $46 \pm 9.5 \mathrm{ml} \cdot \mathrm{min}^{-1} \cdot 1.73 \mathrm{~m}^{-2}$ ) and the second $90-\min \left(49.5 \pm 9.8 \mathrm{ml} \cdot \mathrm{min}^{-1} \cdot 1.73 \mathrm{~m}^{-2}\right)$ experimental periods. The average percent changes were modest and not significant, ranging between -2 and $8 \%$ (Fig. 1 ).

$\mathrm{PAH}$ clearance was similar during euglycaemia in the two studies and rose significantly $(p<0.05)$ during hyperglycaemia in the isotonic saline study only. During hyperglycaemia FF did not rise in either study. After LAS administration FF was significantly lower under both glycaemic conditions than in the isotonic saline study $(p<0.05)$. Renal vascular resistance was similar in both studies during euglycaemia and did not change in hyperglycaemia (Table 2). In the sustained euglycaemia isotonic saline control study no significant changes were found in PAH clearance, $\mathrm{FF}$ and renal vascular resistance (not shown). Mean blood pressure was similar in both studies during euglycaemia (isotonic saline vs LAS:
Table 1. Glomerular filtration rate in eight Type 1 diabetic patients during euglycaemia (Eugl) and hyperglycaemia (Hypergl) after isotonic saline or lysine-acetylsalicilic acid (LAS) administration

\begin{tabular}{|c|c|c|c|c|}
\hline \multicolumn{5}{|c|}{ Glomerular filtration rate $\left(\mathrm{ml} \cdot \mathrm{min}^{-1} \cdot 1.73 \mathrm{~m}^{-2}\right)$} \\
\hline \multirow[b]{2}{*}{ Subjects } & \multicolumn{2}{|c|}{ Isotonic saline } & \multicolumn{2}{|l|}{ LAS } \\
\hline & EugI & Hypergl & Eugl & Hypergl \\
\hline 1 & 42.5 & 54.4 & 24.7 & 27.7 \\
\hline 2 & 50.3 & 67.3 & 19.3 & 21.0 \\
\hline 3 & 25.5 & 30.5 & 28.6 & 30.9 \\
\hline 4 & 51.5 & 71.3 & 54.0 & 62.0 \\
\hline 5 & 68.2 & 75.0 & 56.1 & 56.9 \\
\hline 6 & 29.0 & 31.0 & 12.0 & 16.0 \\
\hline 7 & 28.0 & 48.0 & 19.0 & 25.0 \\
\hline 8 & 37.0 & 62.0 & 27.0 & 44.0 \\
\hline $\begin{array}{l}\text { Mean } \pm \\
\text { SEM }\end{array}$ & $41.5 \pm 5.2^{\mathrm{a}, \mathrm{b}}$ & $55.0 \pm 6^{a}$ & $30.0 \pm 5.7^{b, c}$ & $35.4 \pm 6.0^{\circ}$ \\
\hline
\end{tabular}

${ }^{a} p<0.005$ Euglycaemia vs hyperglycaemia, isotonic saline study. ${ }^{\mathrm{b}} p<0.05$ Isotonic saline vs LAS in euglycaemia. ${ }^{c} p<0.05$ Euglycaemia vs hyperglycaemia, LAS study.

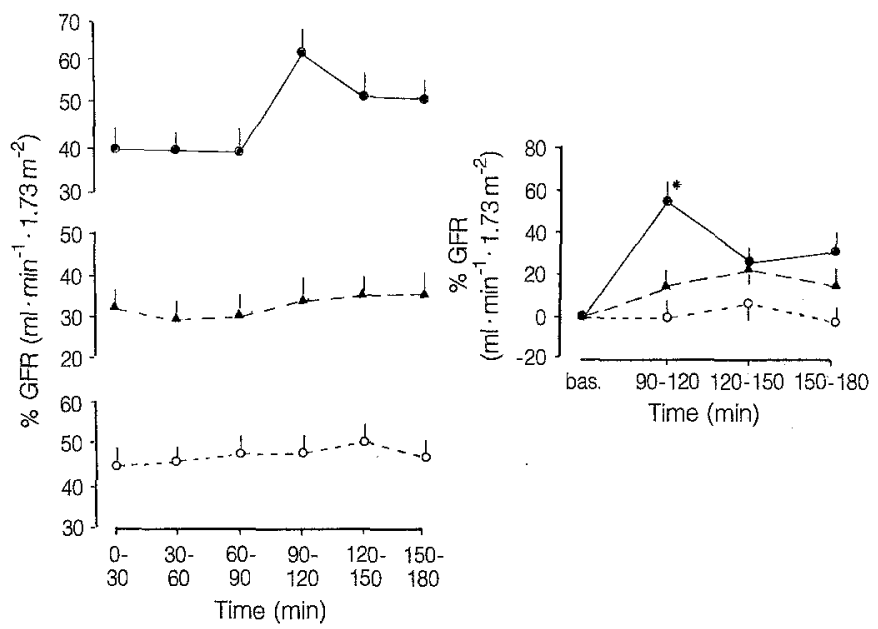

Fig. 1. Glomerular filtration rate (GFR) during euglycaemic (0$90 \mathrm{~min}$ ) and hyperglycaemic clamp (90-180 $\mathrm{min}$ ) after isotonic saline (left side, $-\bullet$ ) and lysine-acetylsalicilic acid administration (left side, $\boldsymbol{\sim} \rightarrow \mathbf{A}$ ) and during sustained euglycaemic isotonic saline control experiments (left side, $0-\infty$ ) in Type 1 diabetic patients with nephropathy. The inset shows the percent change in GFR over the second $90-\mathrm{min}$ period compared to baseline $(0-90 \mathrm{~min})$ for the three experimental conditions illustrated. * $p<0.05$ hyperglycaemic isotonic saline study vs hyperglycaemic lysine-acetylsalicilic acid study

$104 \pm 12$ vs $103 \pm 11 \mathrm{~mm} \mathrm{Hg}$ ) and did not change after hyperglycaemia (106 \pm 15 vs $105 \pm 12 \mathrm{~mm} \mathrm{Hg}$, respectively). Arterial pressure was similarly stable in the euglycaemia isotonic saline control study.

Haematocrit and total protein concentrations were similar during euglycaemia and fell in both studies to a similar extent during hyperglycaemia (Table 3 ). By contrast in the sustained euglycaemia isotonic saline control study haematocrit was unchanged (mean \pm SEM $38.6 \pm 1.8$ vs $38.5 \pm 2.3 \%)$ and total protein concentration stable $(61.8 \pm 4.1$ vs $61.0 \pm 4.4 \mathrm{~g} / 1)$. The fractional clearance of albumin and $\mathrm{IgG}$, measured in seven patients were similar in the two studies during euglycaemia and remained unchanged by hyperglycaemia (euglycaemia vs hyperglycaemia: isotonic saline: albumin: $2.9 \pm 1.2$ vs 
Table 2. Mean \pm SEM, sodium paraminohippurate $(\mathrm{PAH})$ clearance, filtration fraction and renal vascular resistance in eight Type 1 diabetic patients during euglycaemia and hyperglycaemia after isotonic saline or lysine-acetylsalicilic acid (LAS) administration

\begin{tabular}{lll}
\hline Study & Euglycaemia & Hyperglycaemia \\
\hline $\begin{array}{lll}\text { PAH Clearance } \\
\text { ml } \text { min }^{-1} \cdot 1.73 \mathrm{~m}^{-2}\end{array}$ & \\
Isotonic saline & $176 \pm 22.4^{\mathrm{a}}$ & $220 \pm 29.4^{\mathrm{a}}$ \\
LAS & $170 \pm 18.9$ & $206 \pm 26.6$ \\
Filtration fraction & & \\
Isotonic saline & $0.23 \pm .03^{\mathrm{b}}$ & $0.25 \pm .02$ \\
LAS & $0.17 \pm .13^{\mathrm{b}}$ & $0.17 \pm .02$ \\
Renal vascular resistance & & \\
mm Hg min $^{-1} \cdot 1^{-1}$ & & \\
Isotonic saline & $378.0 \pm 72.0$ & $309.0 \pm 43.0$ \\
LAS & $392.0 \pm 50.0$ & $331.0 \pm 82.0$ \\
\hline
\end{tabular}

${ }^{\mathrm{a}} p<0.05$ Euglycaemia vs hyperglycaemia. ${ }^{\mathrm{b}} p<0.05$ Isotonic saline vs LAS

Table 3. Mean \pm SEM haematocrit and total plasma protein concentrations in eight Type 1 diabetic patients during euglycaemia and hyperglycaemia after isotonic saline or lysine-acetylsalicilic acid (LAS) administration

\begin{tabular}{lll}
\hline Study & Euglycaemia & Hyperglycaemia \\
\hline Haematocrit (\%) & & \\
Isotonic saline & $36.5 \pm 1.8$ & $34.2 \pm 1.5^{\mathrm{a}}$ \\
LAS & $37.3 \pm 2.4$ & $35.3 \pm 2.2^{\mathrm{a}}$ \\
Total protein (g/l) & & \\
Isotonic saline & $70.4 \pm 3.8$ & $65.4 \pm 3.4^{\mathrm{a}}$ \\
LAS & $73.8 \pm 2.1$ & $70.0 \pm 1.2^{\mathrm{a}}$ \\
\hline
\end{tabular}

${ }^{a} p<0.005$ euglycaemia vs hyperglycaemia

$3.3 \pm 1.3 \times 10^{-4} ; \operatorname{IgG} 6.7 \pm 0.9$ vs $7.2 \pm 0.8 \times 10^{-6} ;$ LAS: albumin: $1.9 \pm 0.8$ vs $2.4 \pm 1.02 \times 10^{-4}$; IgG: $5.4 \pm 1.1$ vs $\left.6.5 \pm 0.9 \times 10^{-6}\right)$.

\section{Discussion}

Blood glucose concentration contributes to the regulation of GFR in diabetes mellitus. In normoalbuminuric Type 1 diabetic patients acute rises in glycaemia have been reported by several $[1,2]$, though not all [18], authors to be accompanied by a significant but modest increase in GFR of about $6-10 \%$. A condition of moderate hyperglycaemia is associated with a raised GFR both in diabetic humans [18] and streptozotocin diabetic rats [19] compared to euglycaemic diabetic animals and humans. Whether it is the euglycaemia or the concomitant hyperinsulinaemia which lowers the GFR remains debatable in as much as hyperglycaemic hyperinsulinemia has been found to be associated with lower GFR in diabetic rats [19] but not in diabetic humans [5].

The present study showed that also in advanced diabetic renal disease rapid changes in blood glucose levels importantly modulate glomerular haemodynamics, confirming our previous observation of an association between hyperglycaemia and raised GFR [9]. An acute rise in blood glucose led to a simultaneous increase in GFR of about $35 \%$, a change of greater magnitude than that induced by glucose in normoalbuminuric diabetic patients $[1,2]$. No significant changes in GFR were detected in the sustained euglycaemia isotonic saline control experiment, in accord with previous reports $[1,20]$, supporting the view that the GFR change, seen during hyperglycaemia, was mediated by glucose, and not by the salt or water load.

Our findings demonstrate that the GFR response to hyperglycaemia is rapid, occurs within the first $30 \mathrm{~min}$ and is maintained for as long as the hyperglycaemia persists. In the acute setting of the present experiment a rise in blood glucose, during the isotonic saline hyperglycaemia study, led to a significant increase in renal plasma flow, without changes in FF. This is probably the consequence of glucose-induced volume expansion, as indicated by a significant fall in haematocrit and plasma protein concentration. This interpretation is supported by the observation that during sustained euglycaemia, but under the same condition of fluid administration, the changes in haematocrit and plasma protein were small and not significant. In our previous report [9] hyperglycaemia was associated with no changes in renal plasma flow and higher FF; in that study however renal haemodynamic variables were measured on two separate occasions either during sustained euglycaemia or sustained hyperglycaemia and there was no indication of any variation in plasma volume between the two experimental conditions. This was probably due to plasma volume resetting after a prolonged period of raised blood glucose.

Acute hyperglycaemia led to no changes in the fractional clearance of albumin and IgG as previously reported in Type 1 diabetic patients without renal disease [1]. These findings are consistent with the view that the glucose-induced rise in GFR is most likely the result of changes in ultrafiltration coefficient and in membrane permeability to water and small molecules [9].

Our data also indicate that the ability of the GFR to expand is not lost in overt diabetic nephropathy, as implied by studies which tested the renal response to a protein load $[21,22]$, and raise the question of the stimulus dependence of the renal response. That different stimuli may lead to different renal haemodynamic changes is also supported by a study in which significant increases in GFR were noted in proteinuric diabetic patients in response to ketone body infusion [20].

Whether vasodilatory prostaglandins (PG) contribute to the glomerular hyperfiltration of early diabetes remains controversial. Studies of the effect of cyclooxygenase inhibition on glomerular hyperfiltration in the intact diabetic animal have yielded conflicting results. Craven et al. [23] found that indomethacin reduced hyperfiltration in rats 9 to 15 days after induction of diabetes but did not do so at 25 to 28 days. Production of $\mathrm{PGE}_{2}, 6$ keto-PGF $\alpha$ and thromboxane $\mathrm{B}_{2}$ from glomeruli isolated from these rats were higher 9 to 15 days but not 25 to 28 days after streptozotocin injection, suggesting that, perhaps, different mechanisms are involved in the elevation of GFR at different time points in the course of diabetes. Moel et al. [24] reported similar results using aspirin but other authors found that indomethacin administration significantly 
reduced GFR or prevented the rise in GFR in rats 3 months or 28 days after the induction of diabetes, respectively [25-26]. Acute intravenous administration of indomethacin in rats 7 to 10 days after the onset of diabetes failed to reduce GFR [27]. The reasons for these discrepancies are unclear but differences in the duration of diabetes, the degree of blood glucose control and insulin treatment, the salt and water balance at the time of the study, the type and duration of cyclooxygenase inhibition might have all contributed. In the perfused kidney of the diabetic male Sprague-Dawley rat the increased vasodilation and glomerular filtration rate induced by glucose infusion was totally prevented by the administration of a prostaglandin synthase inhibitor, supporting the view that the glucose-induced renal effect may be prostaglandin mediated [28].

Findings in studies in humans with short-term diabetes are also not uniform. Esmatjes et al. [29] found that administration of acetylsalicilic acid reduced GFR in nonproteinuric Type 1 diabetic patients but Christiansen et al. [30] were unable to lower GFR by 3-day administration of indomethacin in newly-diagnosed juvenile diabetic patients. Viberti et al. [31] reported that the urinary excretion of 6-keto-PGF $\alpha$ was significantly raised in Type 1 diabetic patients with glomerular hyperfiltration and Gambardella et al. [32] also demonstrated that raised GFR in newly-diagnosed Type 1 diabetic patients depends, at least partly, on altered renal synthesis of vasodilatory prostacyclin.

Our data in proteinuric diabetic patients with renal failure, and thus at a much later stage of evolution of their disease than in any of the studies previously quoted, strongly implicate vasodilatory prostaglandins in the regulation of GFR both under euglycaemic conditions and in response to glucose-induced hyperglycaemia. Hommel et al. [33] also reported a significant fall in GFR after indomethacin administration in Type 1 diabetic patients with proteinuria and GFR still within the normal range.

Although urinary prostaglandins were not measured in the present study, due to the potential confounding effect of high urine flow rate [34], other workers have demonstrated that administration of $450 \mathrm{mgLAS}$ significantly inhibits renal prostaglandin production $[35,36]$. That the effect is likely to be due to vasodilatory prostaglandins is further supported by recent studies demonstrating that selective inhibition of thromboxane synthesis has no effect on renal haemodynamics in proteinuric Type 1 diabetic patients [37].

Administration of LAS resulted in lower GFR and FF during euglycaemia and in a blunting of the renal haemodynamic response to hyperglycaemia. Changes in other variables such as haematocrit, plasma protein concentration and blood pressure, which could have affected the renal haemodynamic response, cannot account for the results in as much as these parameters were similar during the isotonic saline and LAS hyperglycaemic studies. Antihypertensive therapy was stopped for a $36 \mathrm{~h}$ period and its potential effect on renal haemodynamics may not have been totally eliminated. However, this is unlikely to have significantly affected our results in that the patients acted as their own control in a randomized cross-over study de- sign, thus minimizing the risk of significant bias. The smaller effect of LAS on renal plasma flow either during euglycaemia or in response to hyperglycaemia suggests that inhibition of vasodilatory prostaglandin mainly affects contractile elements within the glomerulus or in the efferent arteriole [38, 39], although, during hyperglycaemia, a more pronounced effect of glucose on the afferent arteriole could also partly account for this finding.

In conclusion, in diabetic renal failure prostaglandins appear to contribute to the blood-glucose-induced elevation of GFR and are important for the regulation of GFR under euglycaemic conditions. This finding is consistent with reports in other renal diseases demonstrating the central role of renal prostaglandin in the maintenance of GFR in damaged kidneys [40]. The prognostic implication of hyperglycaemia-induced higher GFR in diabetic renal failure remains to be elucidated.

Acknowledgements. This study was partly supported by grants from the British Diabetic Association and the Department of Health. SDC was a visiting Research Fellow supported by Ospedale "Casa Sollievo della Sofferenza", San Giovanni Rotondo, Italy. PR was a visiting Research Fellow from Istituto di Ricerche Farmacologiche "Mario Negri" Sezione Nefrologia, Bergamo, Italy.

Part of this paper was presented in abstract form at the $25^{\text {th }}$ EASD Meeting, Lisbon, Portugal September 1989.

\section{References}

1. Christiansen JS, Frandsen M, Parving HH (1981) Effects of intravenous glucose infusion on renal function in normal man and in insulin-dependent diabetics. Diabetologia 21:368-373

2. Wiseman MJ, Mangili R, Alberetto M, Keen H, Viberti GC (1987) Mechanisms of the glomerular response to glycaemic changes in insulin-dependent diabetic subjects. Kidney Int 31: 1012-1018

3. Zatz R, Meyer TW, Rennke HG, Brenner BM (1985) Predominance of haemodynamic rather than metabolic factors in the pathogenesis of diabetic glomerulopathy. Proc Natl Acid Sci USA 82: 5963-5967

4. Mogensen CE, Christensen CK (1984) Predicting diabetic nephropathy in insulin-dependent patients. N Engl J Med 311: 8993

5. Christiansen JS, Frandsen M, Parving H-H (1981) The effect of intravenous insulin infusion on kidney function in insulin-dependent diabetes mellitus. Diabetologia 20: 199-204

6. Parving H-H, Rutili F, Granath K et al. (1979) Effect of metabolic regulation on renal leakiness of dextran molecules in short term insulin dependent diabetics. Diabetologia 17: 157-160

7. Wiseman MJ, Saunders AJ, Keen H, Viberti GC (1985) Effect of blood glucose control on increased glomerular filtration rate and kidney size in insulin-dependent diabetes. $\mathrm{N}$ Engl J Med 312: $617-621$

8. Tuttle KR, Bruton JL, Perusek MC, Lancaster JL, Kopp DT, De Fronzo RA (1991) Effect of strict glycaemic control on renal haemodynamic response to aminoacids and renal enlargement in insulin-dependent diabetes mellitus. N Engl J Med 324: 16261632

9. Remuzzi A, Viberti GC, Ruggenenti P, Battaglia C, Pagni R, Remuzzi G (1990) Glomerular response to hyperglycaemia in human diabetic nephropathy. Am J Physiol 259: F545-F552

10. Smith HW (1951) Measurement of the filtration rate in the kidney. Oxford University Press, New York, pp 39-62

11. Wiseman MJ, Viberti GC, Keen H (1981) Threshold effect of plasma glucose in the glomerular hyperfiltration of diabetes. Nephron 38: 257-260 
12. De Fronzo R, Tobin JD, Andres R (1979) Glucose clamp technique: a method for quantifying insulin secretion and resistance. Am J Physiol 237: E214-E225

13. Dalton RN, Wiseman MJ, Turner C, Viberti GC (1988) Measurements of urinary para-aminohyppuric acid in glycosuric diabetics. Kidney Int 34: 117-120

14. Dalton RN, Turner C (1987) A sensitive method for the measurement of inulin. Ann Clin Biochem 24 [Suppl 1]: 231

15. Bratton AC, Marshall EK (1938) A new coupling component for sulphanilamide determination. J Biol Chem 128: 537-550

16. Bakker AJ (1988) Immunoturbidimetry of urinary albumin: prevention of absorption of albumin; influence of other urinary constituents. Clin Chem 34: 82-86

17. Voller A, Bidwell DE, Bartlett A (1979) The enzyme linked immunosorbent assay (ELISA). A guide with abstracts of microplate applications. Dynatech Europe, Guernsey, pp 14-15

18. Skott P, Vaag A, Hother-Nielsen O et al. (1991) Effects of hyperglycaemia on kidney function, atrial natriuretic factor and plasma renin in patients with insulin-dependent diabetes mellitus. Scand J Clin Lab Invest 51:715-727

19. Scholey JW, Meyer TW (1989) Control of glomerular hypertension by insulin administration in diabetic rats. J Clin Invest 83: 1384-1389

20. Nosadini R, Trevisan R, Fioretto P et al. (1989) Kidney hemodynamics after ketone body and amino acid infusion in normal and IDDM subjects. Diabetes 38: 75-83

21. Bosh JP, Lauren A, Glabman S (1984) Short term protein load in assessment of patients with renal disease. Am J Med 77: 873-879

22. Pinto JR, Bending JJ, Dodds RA, Viberti GC (1991) Effect of low protein diet on the renal response to meat ingestion in diabetic nephropathy. Eur J Clin Invest 21: 175-183

23. Craven PA, Caines MA, DeRubertis FR (1987) Sequential alterations in glomerular prostaglandin and thromboxane synthesis in diabetic rats: relationship to the hyperfiltration in early diabetes. Metabolism 36: 95-103

24. Moel DI, Safirstein RL, McEvoy RC, Husueh EW (1987) Effect of aspirin on experimental diabetic nephropathy. J Lab Clin Med 110: $300-307$

25. Jensen PK, Steven K, Blaehr H, Christiansen JS, Parving H-H (1986) Effects of indomethacin on glomerular haemodynamics in experimental diabetes. Kidney Int 29: 490-495

26. Kirschenbaum MA, Chaudhari A (1986) Effect of experimental diabetes on glomerular filtration rate and glomerular prostanoid production in the rat. Min Electrolyte Metab 12: 352-355

27. Bank N, Lahorra MAG, Aynedjian HS, Schlondorff D (1988) Vasoregulatory hormones and the hyperfiltration of diabetes. Am J Physiol 254: F202 F209

28. Kasiske BL, O'Donnell MP, Kean WF (1985) Glucose-induced increase in renal haemodynamic function. Diabetes 34:360-364
29. Esmatjes E, Fernandez MR, Halperin I et al. (1985) Renal haemodynamic abnormalities in patients with short-term insulin-dependent diabetes mellitus: role of renal prostaglandins. J Clin Endocrinol Metab 60: 1231-1236

30. Christiansen JS, Feldt-Rasmussen B, Parving HH (1985) Shortterm inhibition of prostaglandin synthesis has no effect on the elevated glomerular filtration rate of early insulin-dependent diabetes. Diabetic Med 2: 17-20

31. Viberti GC, Benigni A, Bognetti E, Remuzzi G, Wiseman MJ (1989) Glomerular hyperfiltration and urinary prostaglandins in type 1 diabetes mellitus. Diabetic Med 6:219-223

32. Gambardella S, Andreani D, Cancelli A et al. (1988) Renal hemodynamics and urinary excretion of 6-keto-PG1 alfa and thromboxane $\mathrm{B} 2$ in newly diagnosed type 1 diabetic patients. Diabetes 37: 1044-1048

33. Hommel E, Mathiesen E, Arnold-Larsen S et al. (1987) Effect of indomethacin on kidney function in type 1 (insulin-dependent) diabetic patients with nephropathy. Diabetologia 30: 78-81

34. Francos JA, Eskin SG, McIntyre LV, Ives CL (1985) Flow effects on prostacyclin production by cultured human endothelial cells. Science 227: 1477-1479

35. Arroyo V, Planas R, Gaya J et al. (1983) Sympathetic nervous activity, renin angiotensin system and renal excretion of prostaglandin E2 in cirrhosis. Relationship to functional renal failure and sodium and water excretion. Eur J Clin Invest 13: 271

36. Perea-Ayuso RM, Arroyo V, Camps J et al. (1984) Evidence that renal prostaglandins are involved in renal water metabolism in cirrhosis. Kidney Int 26: 72

37. Kontessis PS, Jones SL, Barrow SI et al. (1993) Effect of selective inhibition of thromboxane synthesis on renal function in diabetic nephropathy. J Lab Clin Med 121: 415-423

38. Dunn MJ, Scharschmidt LA (1987) Prostaglandins modulate the glomerular action of angiotensin II. Kidney Int 31 [Suppl 20]: S95-S101

39. Schlondorff D, Ardaillou R (1986) Prostaglandin and other arachidonic acid metabolites in the kidney. Kidney Int 29: 108-119

40. Kimberly RP, Plotz PH (1977) Aspirin-induced depression of renal function. N Engl J Med 296: 418-424

Received: 1 September 1992

and in revised form: 26 February 1993

Dr S. De Cosmo

Department of Endocrinology

I.R.C.C.S. "Casa Sollievo della Sofferenza"

Viale dei Cappuccini

San Giovanni Rotondo

Italy 